\title{
Effects of androgen substitution on lipid profile in the adult and aging hypogonadal male
}

\author{
F Schleich and J J Legros \\ Endocrinology Service, Interdisciplinary Aging Male Clinic, Faculty of Medicine, University of Liège, CHU Sart Tilman, 400O Liège 1, Belgium \\ (Correspondence should be addressed to J J Legros; Email: Jean-Jacques.Legros@ulg.ac.be)
}

\begin{abstract}
The decrease in serum bioavailable testosterone may be responsible for the catabolic sequelae noticed in the aging man (decrease in libido, decrease in muscle mass, osteoporosis and increase in adiposity). After a brief review of androgen and lipid metabolism as well as their modifications with aging, we discuss current knowledge of the effects of androgen substitution on the lipid profile in hypogonadal men. The results of studies concerning the effect of androgen substitution therapy on lipids are conflicting but might be favorable. The small decrease in high-density lipoprotein cholesterol observed when administering standard dosages of testosterone is accompanied by a significant decrease in total cholesterol (CT) and low-density lipoprotein cholesterol. A counterbalancing of these effects plausibly accounts for the absence of increase cardiovascular risk. The currently available preparations are oral, injectable or transdermal formulations of natural testosterone. The development of new androgen preparations that are more potent, metabolically stable and tissue-specific will improve therapeutic benefits and reduce side effects.
\end{abstract}

European Journal of Endocrinology $151415-424$

\section{Introduction}

Unlike the menopause, reproductive aging in men, also called the 'andropause', is a gradual process, developing over several decades, so that some authors prefer the term 'PADAM' (partial androgen deficiency of aging male). Between a widely deficient and a perfect endocrine function, there is an intermediate zone of functioning manifested as low normal hormonal activity obtained at the cost of significant pituitary hyperstimulation. Testosterone production, essentially its free or biologically active fraction, decreases constantly from the age of 30 years. The decline of testosterone is very different between individuals. As men age, changes occur, such as decreases in muscle mass, libido and bone mineral density and an increase in fat mass (Fig. 1).

Similar changes also occur in men with severe hypogonadism, suggesting that the changes associated with aging might be a consequence of the decrease in testosterone with age (1). Hence, it has been tempting to recommend treating hypogonadal andropausal men with replacement therapy. Previous studies have shown that testosterone increased lean mass and decreased fat mass in otherwise healthy elderly men (2). Such a benefit requires severe endocrine deficiency and persistent tissue sensitivity to androgens. However, there is still reluctance to prescribe this treatment because of the deleterious effects it might have (adverse changes in serum lipid levels, prostatic hypertrophy, growth of pre-existing prostate cancer, sleep apnea and undesirable increases in the hematocrit). We will review the current data concerning the effects of androgen substitution on the lipid profile in hypogonadal men.

\section{Normal androgen metabolism}

Testosterone is a steroid secreted by Leydig cells of the testes. Its production is regulated by a negative feedback system involving gonadatropin-releasing hormone and luteinizing hormone (LH). Testosterone is normally secreted in a circadian rhythm, with high levels in the morning and low levels between 2000 and $2200 \mathrm{~h}$. Along with the testes, which produce $0.24 \mu \mathrm{mol} /$ day of testosterone, the adrenal cortex produces $0.002 \mu \mathrm{mol} /$ day of androgen, mainly as androstenedione (3). Testosterone secretion in males begins in fetal life, with peak concentrations seen at 12 weeks of gestation. Pulsatile secretion of gonadotropin-releasing hormone and LH begins at the onset of puberty and results in the maturity of the Leydig cells.

Testosterone has both direct and indirect actions. In addition to direct activation of the androgen receptor (as in muscle), testosterone has potent bioactive steroid metabolites: $5 \alpha$-dihydrotestosterone (DHT) (nonaromatizable), formed by the enzyme $5 \alpha$-reductase (as in skin and prostate), and $17 \beta$-estradiol, formed by the enzyme aromatase (as in bone and brain) (Fig. 2). The major 


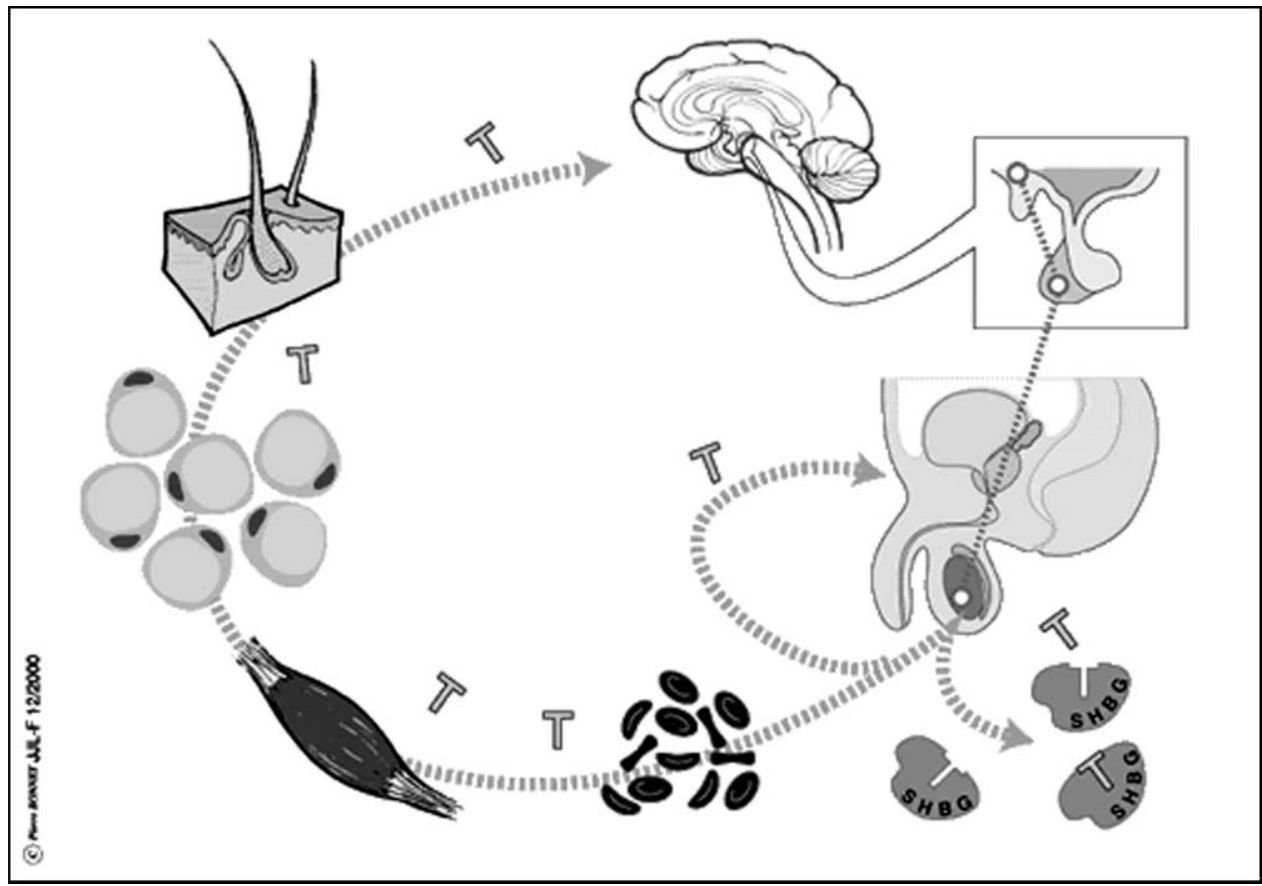

Figure 1 Androgens have many important physiological actions, including effects on muscle, bone, central nervous system, prostate, bone marrow, and sexual function. T, testosterone; SHBG, sex-hormone-binding globulin.

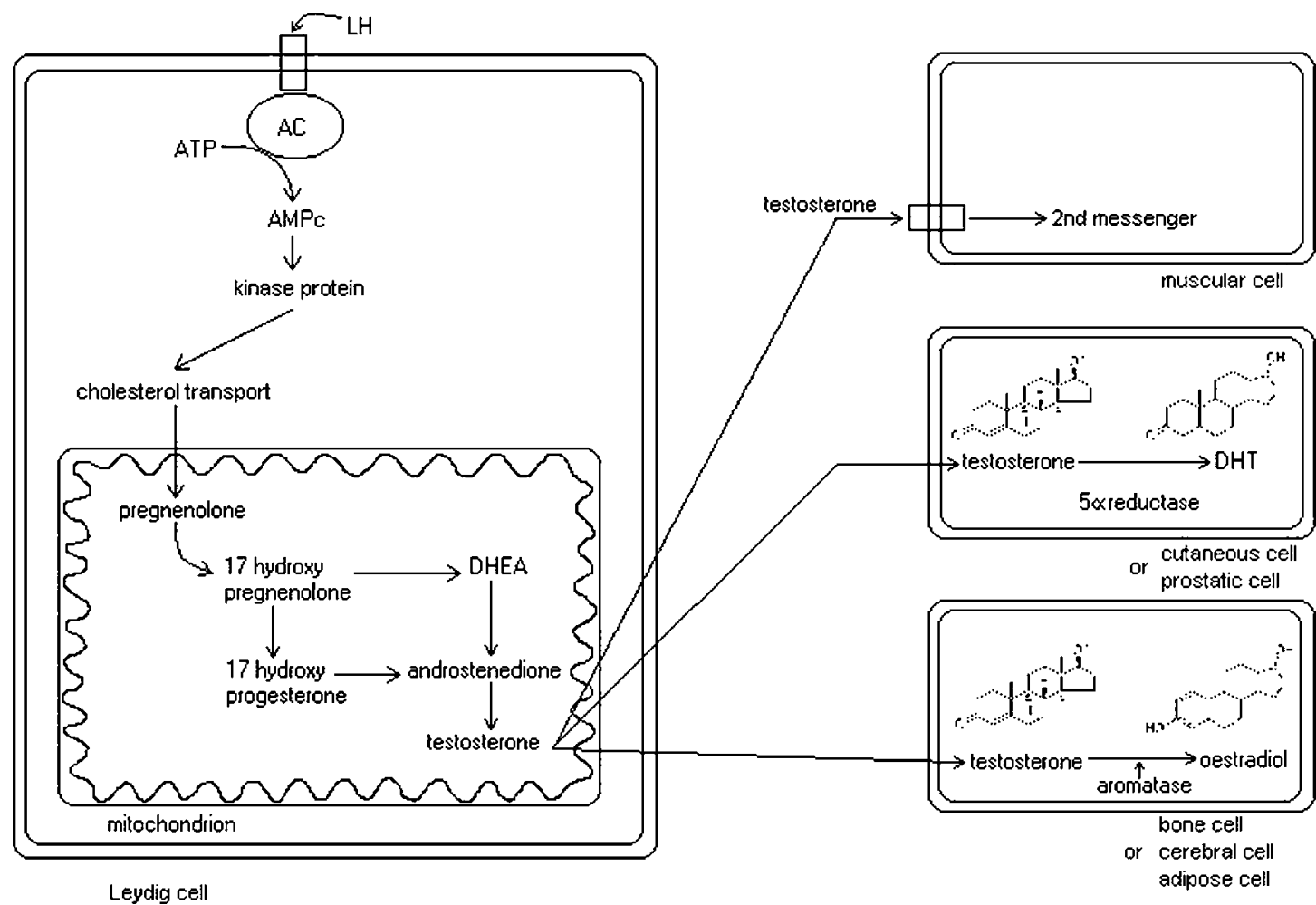

Figure 2 Testosterone has both direct and indirect actions. In addition to direct activation of the androgen receptor (e.g. in muscle (6)) testosterone has patent bioactive steroid metabolites: $5 \alpha$-dihydrotestosterone (DHT) (nonaromatizable), formed by the enzyme $5 \alpha$-reductase (e.g. in skin and prostate) and 17ß-estradiol, formed by the enzyme aromatase, e.g. in bone and brain. 
part of testosterone that circulates in the bloodstream is bound to proteins, either tightly to sex-hormone-binding globulin (SHBG) (inactive testosterone) or more loosely to albumin. The bioavailable testosterone is the unbound testosterone or 'free testosterone' $( \pm 2 \%)$ and the testosterone loosely bound to albumin $( \pm 58 \%)$ (4). The dosage of the bioavailable testosterone is closely related to the biologic activity. This can be achieved with precipitation of SHBG (and bound testosterone) by ammonium sulfate, followed by a radioimmunologic dosage of testosterone (5).

\section{Changes in the hypothalamo-pituitary- gonadal axis with aging}

Numerous cross-sectional investigations have demonstrated lower concentrations of circulating testosterone and/or free testosterone in older men (7-12). Two small-scale longitudinal investigations showed decreases in total testosterone in, respectively, 66 men, 41-61 years old, followed for 13 years (13), and 77 men, 61-87 years old, followed for 15 years (14). One longitudinal study in 890 healthy men found that both testosterone and the free testosterone index decreased progressively at a rate that did not vary significantly with age, from the third to the ninth decades (15). Another study, using longitudinal data from the Massachusetts male aging study, showed a decline of $1.6 \% /$ year for total testosterone and $2-3 \%$ /year for bioavailable testosterone (16).

It is now clear that there is a slow but continuous decline in average serum testosterone after the age of 20-30 years (17) (decreasing by up to $1 \%$ per year), with the lowest levels seen in men 70 years of age and older. With aging, serum SHBG concentration increases (12), resulting in a 'free' or bioavailable testosterone level that decreases to a greater extent than total testosterone (18). If hypogonadism is defined strictly on the basis of serum testosterone levels, a significant proportion of men over age 50 would meet the criteria for testosterone replacement. Vermeulen et al. reported that $7 \%$ of individuals have testosterone below normal (normal value established in young men) at $40-60$ years of age, $22 \%$ at $60-80$ and $37 \%$ at over 80 (19). If the requirement of elevated gonadotropin levels is included, still a large number, perhaps $3-4 \%$ of all men in the 40-60-year age group, would be classed as hypogonadal (20).

The decrease in androgen levels with aging is the result of both gonadal failure (primary hypogonadism) and hypothalamic-pituitary failure (secondary hypogonadism). The gonadal failure is explained by a decrease in the number and volume of the Leydig cells (21), impaired steroid hormone biosynthesis (22) and impaired blood supply to the gonads (23). Alterations in the hypothalamic-pituitary compartment include blunted LH response to gonadotropin-releasing-hormone stimulation (24), increased gonadotropic sensitivity to testosterone feedback (25) and loss of diurnal variations in gonadotropin levels (26). Younger men have higher serum testosterone levels in the mornings than in the evenings, but this circadian rhythm is often lost in older men (27). Therefore, the difference between old and young men is greater in the morning, at which time testosterone concentration is higher in young men.

Secondary hypogonadism is evidenced by a low testosterone and a low or low normal LH concentration.

Serum and urinary glucuronide androstenediol, reflecting the activity of androgen, also decreases with aging. Serum testosterone levels vary considerably depending on the overall health of the individual, smoking and alcohol use, obesity and time of sampling. The serum testosterone of healthy elderly men is lower than that of young men but higher than that of sick old men.

Genetic factors certainly intervene, since the variability of serum testosterone levels is less between brothers than in the general population (28).

\section{Lipoproteins: structure and metabolism}

Serum cholesterol is transported by lipoproteins. These play a key role in the cardiovascular disease development. Low-density lipoproteins (LDL), $200 \mathrm{~nm}$ in diameter, are the principal tissue cholesterol purveyors, particularly to organs that require it in large amounts (such as liver, endocrine glands synthesizing steroids and skin). They are derived from very low-density lipoproteins (VLDL) hydrolysis.

Endocytosis of LDL allows delivery of cholesterol esters to tissues. This capture is regulated by the tissue pool of free cholesterol that modulates the LDL receptor expression on the cell membrane. Acetylated LDL and oxidized LDL interact with a recovery receptor situated on the macrophage cellular surface, so permitting intracellular LDL accumulation. This type of process, which forms foam cells, seems to favor the development of atherosclerosis. Ideally, serum LDL levels have to remain lower than $115 \mathrm{mg} / \mathrm{dl}$.

The production rate of high-density lipoproteins (HDL), $100 \mathrm{~nm}$ in diameter, is determined by the hepatic and, to a lesser degree, intestinal synthesis of apoA1 , the main protein constituent of HDL. Their main role is transmitting apoE and $\mathrm{C}$ to very low-density lipoproteins (VLDL) and chylomicrons to allow their catabolism. Small HDL have easier access to cellular surface. This favors capture of free cholesterol excess from tissue and its transport to the liver. There is a negative correlation between serum HDL cholesterol concentration and the development of atherosclerosis. HDL cholesterol (HDL-C) levels higher than $40 \mathrm{mg} / \mathrm{dl}$ seem to protect patients from development of cardiovascular diseases. Ultracentrifugation analysis showed the existence of two major subclasses of HDL. The lipid content of HDL2 (59-67\%) is higher than HDL3 (41-44\%). 
HDL2, which contains more free and ester cholesterol, more phospholipids and fewer glycerides than HDL3, is less dense. The role of HDL2 in the reverse transport of cholesterol is more important than that of HDL3. Two genes involved in the catabolism of HDL are upregulated by testosterone, namely, hepatic lipase (HL) and scavenger receptor B1 (SR-B1). SR-B1 mediates the selective uptake of HDL lipids into hepatocytes and steroidogenic cells, including Sertoli and Leydig cells of the testes, as well as cholesterol efflux from peripheral cells, including macrophages. Testosterone upregulates SR-B1 in the human hepatocyte cell and in macrophages and thereby stimulates selective cholesterol uptake and cholesterol efflux respectively. HL hydrolyzes phospholipids on the surface of HDL, thereby facilitating the selective uptake of HDL lipids by SR-B1. The activity of HL is increased after administration of exogenous testosterone. The increases in both SR-b1 and HL activities are consistent with the HDLlowering effect of testosterone. It also explains why testosterone induces the most prominent changes in HDL subclasses HDL2 and LpA-I, because these molecules are preferred substrates of HL and SR-B1 to small HDL3 and apoA-II-containing HDL. Interestingly, in transgenic mice, overexpression of HL caused a dramatic fall in HDL-C, but inhibited rather than enhanced atherosclerosis (29). This demonstrates the difficulty in extrapolating the HDL-lowering effect of testosterone to increased cardiovascular risk.

Unlike the absolute value of $\mathrm{CT}$, HDL or LDL, the LDL/HDL ratio is not used in therapeutic decisions. This ratio, calculated by some clinical biology laboratories, must at present be considered as a simple atherogenic risk indication. Another risk factor for coronary atherosclerosis is lipoprotein (a) $(\mathrm{Lp}(\mathrm{a}))$. It has great structural similarity with human plasminogen, establishing a link between atherosclerosis and thrombosis. Lp(a) has no fibrinolytic activity and seems to be synthesized by the liver from remnants of chylomicron catabolism. It resembles LDL because of the presence of one molecule, apoB-100, and by its high content of cholesteryl esters. Lp(a) differs from LDL by the disulfide bridge binding of apoB to a glycoprotein termed apo(a). Lp(a) levels vary considerably in the population from 0 to $300 \mathrm{mg} / \mathrm{dl}$ with a frequency distribution that is skewed to lower concentrations.

$\mathrm{Lp}(\mathrm{a})$ levels are an independent risk factor for coronary and atherosclerotic vessel disease, especially if the high Lp(a) level coexists with other cardiovascular risk factors. Although genetics has a tremendous influence on $\mathrm{Lp}(\mathrm{a})$ levels (autosomal dominant transmission), administration of testosterone to men significantly decreases serum levels of Lp(a) (independently of E2). It is not known whether changes in $\operatorname{Lp}(\mathrm{a})$ induced by testosterone affect the risk of cardiovascular disease. Estrogen, progestin, growth hormone $(\mathrm{GH})$ and thyroxine (T4) can lower Lp(a) levels. Of special importance is size polymorphism. A genetically determined variable number of kringle IV repeats within apo(a) are inversely correlated with Lp(a) levels.

\section{The effects of aging on lipid metabolism}

In prepubertal children, plasma levels of lipoproteins and triglycerides show no gender difference. During puberty, plasma levels of HDL decline in boys, while plasma triglycerides and LDL increase slightly (30). The plasma HDL levels in elderly men are actually slightly higher than in middle-aged men. This might be associated with the age-dependent circulating androgen decline. LDL and triglycerides levels increase slowly but progressively from the late teenage years to the mid50s, at which point they become relatively constant.

Testosterone and HDL-C concentration are decreased by multiple factors, including disease states, lifestyle (for example, smoking and lack of exercise), intercurrent diseases, high body-mass index and android fat distribution.

\section{The effects of testosterone replacement on lipids in old men}

Studies of the effects of testosterone replacement on lipids are conflicting.

\section{Oral androgen}

Administration of oral nonaromatizable androgen results in a significant increase in LDL-C $(30,31)$ and a decrease in HDL-C levels $(30,31)$. Jockenhovel et al. (31) showed that mesterolone $100 \mathrm{mg}$ orally daily induces an unfavorable change in the lipid profile (Table 1). Actually, mesterolone increases LDL, CT and triglyceride (TG), and decreases HDL. Nevertheless, these results must be adapted because the recommended dosage is $10-50 \mathrm{mg} /$ day. Mesterolone has recently been removed from market because of its significant hepatotoxicity.

At present, the therapeutic scheme recommended for testosterone undecanoate (TU) is administration of an induction dosage of $120-160 \mathrm{mg} /$ day for $2-3$ weeks, followed by a maintenance dosage of 40-120 mg/day. Uyanik et al. (32) observed a favorable effect on lipid

Table 1 Main study results of the effects of androgens on TG, LDL, HDL and CT orally administered in hypogonadal men.

\begin{tabular}{lcccc}
\hline Oral androgens & TG & LDL & HDL & CT \\
\hline Mesterolone (100 mg/day) (31) & $\uparrow \uparrow$ & $\uparrow$ & $\downarrow$ & $\uparrow$ \\
Testosterone undecanoate & $\uparrow$ & $\uparrow$ & $\downarrow$ & $\uparrow$ \\
$\begin{array}{l}\text { (160 mg/day) (31) } \\
\text { Testosterone undecanoate }\end{array}$ & $=$ & $\downarrow$ & $=$ & $\downarrow$ \\
$\begin{array}{l}\text { (120 mg/day) (32) } \\
\text { Testosterone undecanoate }\end{array}$ & $=$ & $=$ & $\downarrow$ & $=$ \\
(160 mg/day) (33) & & & &
\end{tabular}


profile after administration of TU $120 \mathrm{mg}$ daily. However, Wittert et al. (33) and Jockenhovel et al. (31) reported an unfavorable change in the lipid profile in hypogonadal men receiving the maximal recommended dosage (160 mg/day). TU is rarely administered at the maximal dosage of $160 \mathrm{mg}$ per day, which is prescribed for a period of only 2-3 weeks. On the other hand, TU may theoretically be administered continuously at the dosage of $120 \mathrm{mg}$ daily (minimal starting dosage and maximal maintenance dosage recommended). Hence, it seems evident that results concerning administration of TU $120 \mathrm{mg}$ daily have a more important practical value for the clinician.

\section{Transdermal androgen}

Administration of the standard dosage of DHT gel (125-200 mg/day) has a favorable effect on lipids.

Table 2 Main study results of the effects of transdermal androgens on TG, LDL, HDL and CT in hypogonadal men.

\begin{tabular}{lllll}
\hline Transdermal & TG & LDL & HDL & CT \\
\hline Testosterone (5 mg/night) (40) & $=$ & $=$ & $=$ & $=$ \\
Testosterone (6 mg/day) (38) & $=$ & $=$ & $=$ & $=$ \\
Testosterone (2.5 mg/day) (41) & $=$ & $=$ & $=$ & $=$ \\
Testosterone (2.5 mg/day) (37) & $=$ & $=$ & $\downarrow$ & $=$ \\
Testosterone (5 mg/day) (53) & $\uparrow$ & $\downarrow$ & $\downarrow$ & $\downarrow$ \\
Testosterone (35) & & & $\downarrow$ & \\
DHT gel (70 mg/day) (34) & $=$ & $\downarrow$ & $=$ & $\downarrow$ \\
\hline
\end{tabular}

Table 3 Results of a study about the effects of subdermal testosterone implants on TG, LDL, HDL and CT in hypogonadal men.

\begin{tabular}{lcccc}
\hline Subdermal implants & TG & LDL & HDL & CT \\
\hline Testosterone implant (1200 mg) (31) & $\uparrow$ & $\uparrow \uparrow \uparrow$ & $\downarrow$ & $\uparrow \uparrow \uparrow$
\end{tabular}

Transdermal DHT decreases total and LDH-C without changing triglycerides or HDL-C (34). Transdermal testosterone decreases HDL-C and increases the CT/HDL ratio $(35,36)$ (Tables 2 and 3 ). Nevertheless, recent studies show no undesirable effects on lipid metabolism $(37,38)$.

\section{Intramuscular androgens}

Although some studies reported no change in HDL (39-46), intramuscular testosterone seems to result in a decrease in $\operatorname{HDL}(31,47-50)$, LDL $(39,42,43$, $48,49,51)$ and CT $(39,42-44,48,49,51)$ (Table 4). Most of the studies mentioned in this paper use a standard dosage of testosterone esters $(250 \mathrm{mg}$ every 21 days) or an equivalent (200 mg every 15 days or $100 \mathrm{mg}$ every 7 days). The results are conflicting: four studies report an unfavorable effect $(31,47$, $50,52)$, three do not show any adverse effect (40, $48,49)$ and five show a beneficial effect $(39,42-44$, 51). Investigations of the prescription of lower testosterone ester dosage $(41,46)$ found a beneficial effect on serum lipids. Although some studies report an increase in triglycerides under substitution therapy $(31,53)$, there is no consensus regarding deleterious action. Studies in which eugonadal men were rendered hypogonadal, either by administering a gonadotropin-releasing hormone analog or by castration, showed no consistent effects on serum lipids even though the degree of the hypogonadism was much more severe than that encountered in spontaneous hypogonadism. Interpretation is still difficult owing to the acute nature of the insufficiency, which is contrary to the chronic evolution observed in pathologic patterns.

Whistel et al. (49) conducted a meta-analysis to determine whether intramuscular administration of testosterone esters to hypogonadal men is associated with changes in plasma lipids. They attempted to answer four questions. Are the changes homogeneous

Table 4 Main study results of the effects of intramuscular androgens on TG, LDL, HDL and CT in hypogonadal men.

\begin{tabular}{|c|c|c|c|c|}
\hline Intramuscular androgens & TG & LDL & HDL & CT \\
\hline Testosterone enanthate (250 mg/21 days) (31) & $\uparrow$ & $\uparrow$ & $\downarrow$ & $\uparrow$ \\
\hline Testosterone enanthate (200 mg/15 days) (40) & $=$ & $=$ & $=$ & $=$ \\
\hline Testosterone enanthate (100 mg/7 days) (48) & $=$ & $\downarrow$ & $\downarrow$ & $\downarrow$ \\
\hline Testosterone enanthate (50) & $=$ & $=$ & $\downarrow$ & $=$ \\
\hline Testosterone enanthate (200 mg/21 days) (41) & $=$ & $=$ & $=$ & $=$ \\
\hline Testosterone enanthate (200 mg/15 days) (51) & & $\downarrow$ & & $\downarrow$ \\
\hline Testosterone enanthate (250 mg/month) (46) & $=$ & $=$ & Small $\uparrow$ HDL2C $\downarrow$ HDL3C & $=$ \\
\hline Testosterone enanthate (200 mg/15 days) (42) & & $\downarrow$ & $=$ & $\downarrow$ \\
\hline Testosterone enanthate or testosterone cypionate (200 mg/15 days) (47) & & & $\downarrow$ & $=$ \\
\hline Testosterone cypionate $(200 \mathrm{mg} / 15$ days) $(44)$ & $=$ & $=$ & $=$ & $\downarrow$ \\
\hline Testosterone cypionate (43) & & $\downarrow$ & $=$ & $\downarrow$ \\
\hline Testosterone esters (180 mg/15 days) (49) & $=$ & $\downarrow$ & $\downarrow$ & $\downarrow$ \\
\hline \multicolumn{5}{|l|}{ Testosterone proprionate $(30 \mathrm{mg})$} \\
\hline Testosterone phenylproprionate (60 mg) & $=$ & $\uparrow$ & $\uparrow$ HDL2 & $\uparrow$ \\
\hline \multicolumn{5}{|l|}{ Testosterone isocaproate $(60 \mathrm{mg})$} \\
\hline Testosterone decanoate $(100 \mathrm{mg})$ (250 mg/21 days) (52) & & & & \\
\hline
\end{tabular}


between studies? What are the best overall estimates of the changes? How precise and robust are the estimates? Can between-study heterogeneity of the changes be explained? Among the 79 papers, 19 met criteria for critical appraisal and were abstracted. Most of the studies showed no significant effect on HDL. However, the meta-analysis found a small, yet significant decrease in HDL-C concentration among hypogonadal men receiving, on average, standard replacement dosages of intramuscular testosterone. However, the decrease in HDL-C was accompanied by important reductions in both total cholesterol and LDL-C concentration. The magnitude of the decrease in HDL-C also varied inversely with testosterone dosage. Administering intramuscular testosterone esters to hypogonadal men is associated with a small, dosage-dependent reduction of HDL-C concentration and a decrease in total cholesterol and LDL-C.

Several mechanisms explain the effect of androgen on plasma lipids. Androgen increases the activity of hepatic triglyceride lipase, thereby increasing the clearance of HDL-C. This enzyme is inhibited by estrogen (54). This explains why serum HDL-C levels are lower in men than in premenopausal women (55). Testosterone administration results in lipolysis by adipocytes and stimulation of androgen receptors (56). Exogenous testosterone is aromatized in vivo to estradiol, which has a demonstrated importance in maintaining HDL-C concentrations among men. The beneficial effect on LDL is perhaps the result of an increase in estradiol concentration after aromatization of androgen in the adipocytes. Estrogen stimulates LDL receptor expression and therefore its clearance. This hypothesis is reinforced by the observations of Friedle et al. (57), who showed that aromatizable androgen (testosterone) has less detrimental effects on serum lipids than nonaromatizable androgen (DHT).

The diminution of HDL levels observed during substitution therapy is more significant when supraphysiological doses of androgen are administered, nonaromatizable androgen is chosen and androgen is orally administered. The older the treated men and the longer the treatment, the less prominent this decrease of HDL-C appeared to become. Transdermal application of testosterone or DHT also exerted less effect on HDL-C than intramuscular application $(34,53)$.

\section{Androgen, lipid profile and cardiovascular disease}

Among the various known risk factors for coronary artery disease (CAD), five are cited most frequently: hypertension, diabetes mellitus, cigarette smoking, hyperlipidemia and obesity.

The gender disparity in cardiovascular disease has been interpreted primarily as reflecting estrogenmediated potection against atherogenesis, but it should be due to androgen's promoting atherosclerosis. Randomized clinical trials showed no cardiovascular benefits of combined estrogen/progestin therapy in menopausal women (58). Higher male susceptibility to cardiovascular disease may be due to genetic, hormonal or lifestyle factors, or to a combination of mechanisms.

With the prospects of much wider therapeutic applications of androgen, an important clinical question is whether androgen treatment increases the risk or severity of CAD. Testosterone administered to hypogonadal men is associated with a small, dosage-dependent reduction of HDL-C concentration and a decrease in total cholesterol and LDL-C. As indicated earlier, intracellular LDL accumulation seems to favor the development of atheroscerosis. Ideally, serum LDL levels should remain lower than $115 \mathrm{mg} / \mathrm{dl}$. The lowering effect of testosterone on LDL concentration seems to protect against atherogenesis.

Prospective population-based studies suggest that a $1 \mathrm{mg} / \mathrm{dl}$ decrease in HDL-C is associated with a $2-3 \%$ increase in the risk of coronary heart disease. However, there is no increase in angina or myocardial infarctions in patients receiving testosterone for up to 3 years (47), and angiographic studies have also shown no significant relation between levels of sex steroids and CAD in men (59).

A counterbalancing of these effects plausibly accounts for the enigmatic discrepancy between, on the one hand, the absence of association between plasma total testosterone and risk of cardiovascular disease and, on the other hand, the HDL-C-lowering effects of testosterone esters. Lowering of HDL-C by testosterone is considered to increase cardiovascular risk because HDL-C exerts several potentially antiatherogenic actions. However, in transgenic animal models, only increases of HDL-C induced by apoA-I overproduction, but not by inhibition of HDL catabolism, were consistently found to prevent atherosclerosis. Therefore, the mechanism of HDL modification and, by inference, changes in metabolism of HDL-C per se appear to determine the (anti-)atherogenicity of HDL. Androgen-induced declines in circulating HDL-C should not automatically be assumed to be proatherogenic, because these declines may reflect accelerated reverse cholesterol transport instead (60).

The net effect of testosterone on the risk of cardiovascular disease is difficult to assess for at least five main reasons. First, the associations between serum concentrations of endogenous testosterone and cardiovascular-disease risk factors are confounded by mutual interactions between endogenous androgens, body fat distribution and insulin sensitivity. Second, exogenous testosterone has profound effects, some of which appear beneficial, on several risk factors, such as the lowering of fibrinogen, Lp(a), insulin and plasminogen activator inhibitor type 1 (PAI-1), while other effects are considered adverse, namely, the lowering of HDL-C. Third, the causal relationship between risk factors and 
atherosclerosis has not been proven, although it is suspected. Fourth, testosterone exerts its metabolic effects either directly or by means of its metabolites estradiol (E2) and DHT. The effects of testosterone and E2 can be either additive (as on $\operatorname{Lp}(\mathrm{a})$ ) or counter-regulatory (as on HDL-C). Fifth, polymorphisms in the genes of the androgen receptor, SHBG and $5 \alpha$-reductase regulate genomic effects and the bioavailability of testosterone and DHT respectively.

Future study must weigh the potentially detrimental effect of testosterone on HDL-C against its concomitant, possibly beneficial effects on both total cholesterol and LDL-C, as well as its effects on the other predictors of cardiovascular disease such as Lp(a), visceral adiposity, insulin resistance, fibrinolysis and vascular reactivity.

\section{Which molecule?}

With regard to oral administration, it is best to avoid $17 \alpha$-methyltestosterone, fluoxymesterone and $17 \alpha-$ alkyls because these preparations can cause hepatotoxicity; that is, increase in hepatic enzymes, cholestasis and sometimes development of hepatic tumors (61). At present, TU remains the reference molecule in this galenical. Testosterone esters (enanthate, cypionate and propionate) are preferred for intramuscular administration. Their metabolic profile is better than that of nonaromatizable androgen. Testosterone and its derivatives seem to be the best androgens for substitution therapy in hypogonadal men (62).

\section{Choice of testosterone preparation}

In the presence of evidence of androgen deficiency, the initiation and continuation of testosterone replacement therapy is not contraindicated in men with known CAD (63).

Today, oral, injectable, implantable and transdermal testosterone preparations are available for clinical use, and further preparations are under development. They all produce distinct but widely differing pharmacokinetic profiles of serum testosterone. However, the biologic significance of these various profiles is not fully appreciated, as we are only beginning to understand which serum levels and metabolites are required to achieve the various biologic effects of testosterone and to avoid undesired side effects.

Of the available testosterone preparations, the injectable esters (testosterone enanthate, propionate and cypionate) continue to be the most widely used for substitution purposes, and they result in identical serum profiles. The advantage is administration of 'natural' aromatizable testosterone and the diminution of therapeutic nonobservance (one injection every 2-4 weeks). However, if injected at 2-3-week intervals, they initially produce supraphysiologically high serum testosterone levels, which cause side effects. These levels then slowly decrease with progressive recurrence of hypogonadism symptoms (32). Patients recognize and dislike these ups and downs of testosterone levels, paralleled by variations of well-being, sexual activity and emotional stability. This problem is attenuated by using long-acting TU injections (64). However, due to their low solubility, large amounts of these esters are required in a large volume (about $4-8 \mathrm{ml}$ intramuscularly), limiting the acceptability of this therapy. These injections can also be painful.

Subdermal testosterone implants successfully deliver testosterone. The profile of high initial peaks and decline thereafter extends over a much longer period of up to 6 months. The implantation of these testosterone pellets requires a small surgical procedure.

TU administered orally produces short-lived peaks of a few hours duration, so that three doses have to be taken daily to administer enough testosterone for substitution, resulting in an irregular serum testosterone pattern during the course of the day. Oral androgen substitution offers no advantage over parenteral androgen substitution, except its easier oral administration. Some oral preparations have significant hepatotoxicity.

Finally, testosterone administered through either scrotal or nongenital skin produces testosterone profiles mimicking the physiological diurnal variations of testosterone and influencing the lipid profile less (40). The necessity of using ethanol to facilitate absorption through the skin causes a higher rate of skin reactions (65). Hence, while the pharmacokinetic profile fulfills the consensus goal, the inconvenience of having to shave the scrotum occasionally to ensure adhesion of the transcrotal patch prevents some patients from reaping the benefit. Testosterone gel preparations also need to be administered to the skin in relatively large amounts in order to deliver enough testosterone to the systemic circulation. The risk of transfer of hormones to others via skin contact is another disadvantage.

It appears that many of the currently available therapies for androgen replacement have disadvantages. There is a need for androgens that are more potent and metabolically stable and that are more tissue-selective in action in inducing beneficial effects of androgen receptor activation while reducing undesired side effects (66). Due to its higher affinity for the androgen receptor, subdermal implants of $7 \alpha$-methyl-19-nortestosterone are considerably more potent than testosterone. MENT is not potentiated by $5 \alpha$-reductase. Hence, it exerts androgenic activity in muscle and bone while having a lesser effect on the prostate (67). A comparative study (68) shows that the MENT implants were well tolerated and preferred to the frequent injection of testosterone enanthate. A recent abstract showed a decrease in prostate volume while muscle mass increased (69). More data are needed for further evaluation of the clinical effects and long-term safety of MENT, in particular on plasma lipids. Recently, nonsteroid molecules have been identified. These can neither 
be potentiated upon $5 \alpha$-reduction nor aromatized to estrogenic compounds.

New nonsteroid androgens are being developed within Laboratories Organon's research program. LG121071 (70), LGD2226 (71) and androxolutamide (72) are tissue-selective, nonsteroid androgens in an early stage of development. No information is yet available on the effects of these new androgens in humans. The first compound is currently being investigated in early phase I clinical research, and the second compound will enter the early clinical phase soon. LG121071 and LGD2226 have a higher affinity for the human androgen receptor than DHT, are metabolically more stable than testosterone, resulting in good oral efficacy, and have a prostate-sparing effect. These pharmacologic observations in animal models provide a promising basis for further clinical development of these compounds in humans.

\section{General conclusion and prospectives}

The andropause begins at very different times in different individuals. The significant diminution of testosterone levels is responsible for the functional decline observed at this period of life. The results of studies of the effect of androgen substitution therapy on lipids are conflicting but might be favorable. The small decrease in HDL-C observed when administering standard dosages of testosterone is accompanied by a significant decrease in CT and LDL-C. A counterbalancing of these effects plausibly accounts for the absence of increased cardiovascular risk.

The development of new, tissue-selective androgenic compounds (SARMs) may offer many therapeutic benefits. However, much needs to be done to evaluate the clinical efficacy and long-term safety in humans.

\section{References}

1 Mauras N, Hayes V, Welch S, Rini A, Helgeson K, Dokler M, Veldhuis JD \& Urban RJ. Testosterone deficiency in young men: marked alterations in whole body protein kinetics, strength, and adiposity. Journal of Clinical Endocrinology and Metabolism 1998 83 1886-1892.

2 Snyder PJ, Peachey H, Hannoush P, Berlin JA, Loh L, Lenrow DA, Holmes JH, Dlewati A, Santanna J, Rosen CJ \& Strom BL. Effect of testosterone treatment on body composition and muscle strength in men over 65 years of age. Journal of Clinical Endocrinology and Metabolism $1999 \mathbf{8 4} 2467-2653$.

3 Jeffcoate SL, Brocks RV, Lin NY, London DR, Prunty FT \& Spathis GS. Androgen production in hypogonadal men. Journal of Endocrinology $196737401-411$.

4 Wheeler MJ. Determination of bio-available testosterone. Annals of Clinical Biochemistry 199532 345-357.

5 Lejeune H, Déchaud H \& Pugeat M. Contribution of bioavailable testosterone assay for the diagnosis of androgen deficiency in elderly men. Annals of Endocrinologiey $2003 \mathbf{6 4} 117-125$.

6 Liu P, Death A \& Handelsman D. Androgens and cardiovascular disease. Endocrine Reviews 200324 313-340.
7 Vermeulen A, Rubens R \& Verdonck L. Testosterone secretion and metabolism in male senescence. Journal of Clinical Endocrinology and Metabolism 197234 730-735.

8 Bremner WJ \& Prinz PN. A loss of circadian rhythmicity in blood testosterone levels with aging in normal men. Journal of Clinical Endocrinology and Metabolism 198356 1278-1281.

9 Tenover JS, Matsumoto AM, Plymate SR \& Bremner WJ. The effects of aging in normal men on bioavailable testosterone and luteinizing hormone secretion: response to clomiphene citrate. Journal of Clinical Endocrinology and Metabolism $1987 \mathbf{6 5}$ $1118-1126$.

10 Gray A, Berlin JA, McKinlay JB \& Longcope C. An examination of research design effects on the association of testosterone and male aging: results of a meta-analysis. Journal of Clinical Epidemiology $199144671-684$.

11 Ferrini RL \& Barrett-Connor E. Sex hormones and age: a crosssectional study of testosterone and estradiol and their bioavailable fractions in community-dwelling men. American Journal of Epidemiology $1998 \mathbf{1 4 7} 750-754$.

12 Purifoy FE, Koopmans LH \& Mayes DM. Age differences in serum androgen levels in normal adult males. Human Biology 198153 499-511.

13 Zmuda JM, Cauley JA \& Kriska A. Longitudinal relation between endogenous testosterone and cardiovascular disease risk factors in middle-aged men. A 13-year follow-up of former Multiple Risk Factor Intervention Trial participants. American Journal of Epidemiology $1997 \mathbf{1 4 6} 609-617$.

14 Morley JE, Kaiser FE \& Perry HM 3rd. Longitudinal changes in testosterone, luteinizing hormone, and follicle-stimulating hormone in healthy older men. Metabolism $1997 \mathbf{4 6} 410-413$.

15 Harman SM, Metter EJ, Tobin JD, Pearson J \& Blackman MR. Baltimore Longitudinal Study of Aging. Longitudinal effects of aging on serum total and free testosterone levels in healthy men. Journal of Clinical Endocrinology and Metabolism 200186 $724-731$.

16 Feldman HA, Longcope C, Derby CA, Johannes CB, Araujo AB, Coviello AD, Bremner WJ \& McKinlay JB. Age trends in the level of serum testosterone and other hormones in middle-aged men: longitudinal results from the Massachusetts male aging study. Journal of Clinical Endocrinology and Metabolism 200287 589-598.

17 Gray A, Feldman HA, McKinley JB \& Longcope C. Age, disease and changing sex hormone levels in middle-aged men: results of the Massachusetts Male Aging Study. Journal of Clinical Endocrinology and Metabolism 199173 1016-1025.

18 Desylpere JP \& Vermeulen A. Leydig cell function in normal men: effect of age, life-style, residence, diet, and activity. Journal of Clinical Endocrinology and Metabolism 1984 59 955-962.

19 Vermeulen A, Kaufman JM \& Giagulli VA. Influence of some biological indexes on sex hormone-binding globulin and androgen levels in aging or obese males. Journal of Clinical Endocrinology and Metabolism $1996 \mathbf{8 1} 1821-1826$.

20 Feldman HA, McKinlay JB \& Longcope C. Hypogonadism: correlates in a large random sample of Massachusetts men. Proceedings of the 79th Annual Meeting of the Endocrine Society, 1997, pp 1-317.

21 Neaves WB, Johnson L, Porter JC, Parker CR Jr \& Petty CS. Leydig cell numbers, daily sperm production and serum gonadotrophin levels in aging men. Journal of Clinical Endocrinology and Metabolism 198459 756-763.

22 Vermeulen A \& Desylpere JP. Intratesticular unconjugated steroids in elderly men. Journal of Steroid Biochemistry $1986 \mathbf{2 4}$ 1079-1089.

23 Suoranta H. Changes in small blood vessels of the adult human testes in relation to age and some pathological conditions. Virchows Archiv (Pathological Anatomy and Histopathology) 1971352 $765-781$.

24 Vermeulen A, Desylpere JP \& Kaufman JM. Influence of antiopioids and luteinizing hormone pulsatility in aging men. Journal of Clinical Endocrinology and Metabolism 198968 68-72. 
25 Winters SJ, Sherins RJ \& Troen P. The gonadotropin suppressive activity of androgens is increased in elderly men. Metabolism $1984331052-1059$.

26 Desylpere JP \& Vermeulen A. Leydig cell function in normal men: effect of age, lifestyle, residence, diet and activity. Journal of Clinical Endocrinology and Metabolism 198968 68-72.

27 Bremner WJ, Vitiello MV \& Prinz PN. Loss of circadian rhythmicity in blood testosterone levels with aging in normal men. Journal of Clinical Endocrinology and Metabolism 198356 1278-1281.

28 Meikle AW, Stanish WM, Taylor N, Edwards CQ \& Bishop CT. Familial effects on plasma sex-steroid content in man: testosterone, estradiol and sex hormone-binding-globulin. Metabolism $1982316-9$.

29 Von Eckardstein A, Nofjer JR \& Assmann G. HDL and coronary heart disease: role of cholesterol efflux and reverse cholesterol transport. Atheriosclerosis, Thrombosis, and Vascular Biology 2001 20 13-27.

30 Bagatell CJ \& Bremmer WJ. Androgen and progestagen effects on plasma lipids. Progress in Cardiovascular Diseases $19953 \mathbf{8}$ 255-271.

31 Jockenhovel F, Bullmann C, Schubert M, Vogel E, Reinhardt W, Reinwein D, Muller-Wieland D \& Krone W. Influence of various modes of androgen substitution on serum lipids and lipoproteins in hypogonadal men. Metabolism 199948 590-596.

32 Uyanik BS, Ari Z. Gumus B, Yigitoglu MR \& Arslan T. Beneficial effects of testosterone undecanoate on the lipoprotein profiles in healthy elderly men. A placebo controlled study. Japanese Heart Journal 199738 73-82.

33 Wittert GA, Chapman IM, Haren MT, Mackintosh S, Coates P \& Morley JE. Oral testosterone supplementation increases muscle and decreases fat mass in healthy elderly males with lownormal gonadal status. Journal of Gerontology. Series A, Biological Sciences and Medical Sciences 200358 618-625.

34 Ly L, Jimenez M, Zhuang TN, Celermajer DS, Conway AJ \& Handelsman DJ. A double-blind, placebo-controlled, randomized clinical trial of transdermal dihydrotestosterone gel on muscular strength, mobility, and quality of life in older men with partial androgen deficiency. Journal of Clinical Endocrinology and Metabolism 200186 4078-4088.

35 Arver S, Dobs AS, Meikle AW, Caramelli KE, Rajaram L, Sanders SW \& Mazer NA. Long-term efficacity and safety of a permeationenhanced testosterone transdermal system in hypogonadal men. Clinical Endocrinology 199747 727-737.

36 Wang C, Swerdloff R, Iranmanesh A, Dobs A, Snyder PJ, Cunningham G, Matsumoto AM, Weber T \& Berman N. Transdermal testosterone gel improves sexual function, mood, muscle strength, and body composition parameters in hypogonadal men. Testosterone Gel Study Group. Journal of Clinical Endocrinology and Metabolism 200085 2839-2853.

37 Kenny AM, Prestwood KM, Gruman CA, Fabregas G, Biskup B \& Mansoor G. Effects of transdermal testosterone on lipids and vascular reactivity in older men with low bioavailable testosterone levels. Journal of Gerontology. Series A, Biological Sciences and Medical Sciences $2002 \mathbf{5 7}$ 460-465.

38 Snyder PJ, Peachey H, Berlin JA, Rader D, Usher D, Loh L, Hannoush P, Dlewati A, Holmes JH, Santanna J \& Strom BL Effect of transdermal testosterone treatment on serum lipid and apolipoprotein levels in men more than 65 years of age. American Journal of Medicine $2001111255-260$.

39 Zgliczynski S, Ossowski M, Slowinska-Srzednicka J, Brzezinska A, Zgliczynski W, Soszynski P, Chotkowska E, Srzednicki M \& Sadowski Z. Effect of testosterone replacement therapy on lipids and lipoproteins in hypogonadal and elderly men. Atherosclerosis $19962135-43$.

40 Dobs AS, Meikle AW, Aver S, Sanders SW, Caramelli KE \& Mazer NA. Pharmacokinetics, efficacy, and safety of a permeationenhanced testosterone transdermal system in comparison with bi-weekly injections of testosterone enanthate for the treatment of hypogonadal men. Journal of Clinical Endocrinology and Metabolism 199984 3469-3478.
41 Kenny AM, Prestwood KM \& Raisz LG. Short-term effects of intramuscular and transdermal testosterone on bone turnover, prostate symptoms, cholesterol, and hematocrit in men over age 70 with low testosterone levels. Endocrine Research 200026 153-168.

42 Morley JE, Perry HM 3rd, Kaiser FE, Kraenzle D, Jensen J, Houston K, Mattammal M \& Perry HM Jr. Effects of testosterone replacement therapy in old hypogonadal males: a preliminary study. Journal of the American Geriatrics Society 1993 41 149-152.

43 Ellvin FM, Plunkett-Reid K \& Rumilla AE. The long-term beneficial effect of low-dose testosterone in the aging male. Proceedings of the $79^{\text {th }}$ Annual Meeting of the Endocrine Society. Minneapolis, MN, USA, 1997. Abstract P236.

44 Sih R, Morley JE, Kaiser FE, Perry HM 3rd, Patrick P \& Ross C. Testosterone replacement in older hypogonadal men - a 12 month randomized controlled trial. Journal of Clinical Endocrinology and Metabolism 199782 1661-1667.

45 Barret-Connor E. Testosterone, HDL cholesterol, and cardiovascular disease in men. In Pharmacology, Biology, and Clinical Applications of Androgens, pp 215-223. Eds S Bhasin, HL Gabelnick, JM Spieler, RS Swerdloff, C Wang \& C Kelly. New York: Wiley, 1996.

46 Tan KCB, Shiu SWN \& Pang RWC. Effects of testosterone replacement on HDL subfractions and apolipoprotein A-1 containing lipoproteins. Clinical Endocrinology 199848 187-194.

47 Hajjar RR, Kaiser FE \& Morley JE. Outcomes of long-term testosterone replacement in older hypogonadal males. A retrospective analysis. Journal of Clinical Endocrinology and Metabolism 1997 82 3793-3796.

48 Tenover JS. Effects of testosterone supplementation in the aging male. Journal of Clinical Endocrinology and Metabolism 199275 1092-1098.

49 Whistel EA, Boyko EJ, Matsumoto AM, Anawalt BD \& Siscovick DS. Intramuscular testosterone esters and plasma lipids in hypogonadal men: a meta-analysis. American Journal of Medicine 2001 $111261-269$.

50 Berg G, Schreier L, Geloso G, Otero P, Nagelberg A \& Levalle O. Impact on lipoprotein profile after long-term testosterone replacement in hypogonadal men. Hormone and Metabolic Research 2002 34 87-92.

51 Rabijewski M, Adamkiewicz M \& Zgliczynski S. The influence of testosterone replacement therapy on well-being, bone mineral density and lipids in elderly men. Polskie Archiwum Medycyny Wewnetrznej $1998100212-221$.

52 Ozata M, Yildirimkaya M, Bulur M, Bingol N, Beyhan Z, Corakci A, Bolu E \& Gundogan MA. Effects of gonadotropin and testosterone treatments on lipoprotein (a), high density lipoprotein particles, and other lipoprotein levels in male hypogonadism. Journal of Clinical Endocrinology and Metabolism $1996 \mathbf{8 1}$ $3372-3378$.

53 Dobs AS, Bachorik PS, Arver S, Meikle AW, Sanders SW, Caramelli KE \& Mazer NA. Interrelationships among lipoprotein levels, sex hormones, anthropometric parameters, and age in hypogonadal men treated for 1 year with a permeation-enhanced testosterone transdermal system. Journal of Clinical Endocrinology and Metabolism $2001861026-1033$.

54 Kantor MA, Bianchi A, Bernier D, Sady SP \& Thompson PD. Androgens reduce HDL2-cholesterol and increase hepatic triglyceride lipase activity. Medicine and Science in Sports and Exercise $198517462-465$

55 Heiss G, Johnson NJ, Reiland S, Davis CE \& Tyroler HA. The epidemiology of plasma high density lipoproteins cholesterol levels. Circulation 198062 (Suppl) 116-136.

$56 \mathrm{Xu} \mathrm{X}$, De Pergola G \& Bjorntorp P. The effects of androgens on the regulation of lipolysis in adipose precursor cells. Endocrinology $19901261229-1234$.

57 Friedle KE, Hannan C, Jones RE \& Plymate SR. High-density lipoprotein cholesterol is not decreased if an aromatizable androgen is administered. Metabolism 199039 69-74. 
58 Rossouw JE, Anderson GL, Prentice RL, LaCroix AZ, Kooperberg C, Stefanick ML, Jackson RD, Beresford SA, Howard BV, Johnson KC, Kotchen JM \& Ockene J. Writing Group for the Women's Health Initiative Investigators. Risks and benefits of estrogen plus progestin in healthy postmenopausal women: principal results from the Women's Health Initiative randomized controlled trial. Journal of the American Medical Association $2002 \mathbf{2 8 8}$ $321-333$.

59 Hauner H, Stangl K, Burger K, Busch U, Blomer H \& Pfeiffer EF. Sex hormone concentrations in men with angiographically assessed coronary artery disease - relationship to obesity and body fat distribution. Klinische Wochenschrift $199169664-668$.

60 Von Eckardstein A \& Wu FCW. Testosterone and atherosclerosis. Growth Hormone and IGF Research 200313 S72-S84.

61 E Nieschlag \& HM Behre, Eds. Testosterone: Action, Deficiency, Substitution, 2nd edn., Berlin: Springer-Verlag, 1998.

62 Snyder PJ \& Lawrence DA. Treatment of male hypogonadism with testosterone enanthate. Journal of Clinical Endocrinology and Metabolism 198051 1335-1339.

$63 \mathrm{Wu}$ FCW \& von Eckardstein A. Androgens and coronary artery disease. Endocrine Reviews 200324 183-217.

64 Von Eckardstein S \& Nieschlag E. Treatment of male hypogonadism with testosterone undecanoate injected at extended intervals of 12 weeks: a phase II study. Journal of Andrology 200223 419-425.

65 Nieschlag E \& Behre HM. Pharmacology and clinical uses of testosterone. In Testosterone: Action, Deficiency, Substitution, 2nd edn, pp 293-328 Eds. E Nieschlag \& HM Behre. Berlin: Springer-Verlag, 1998.

66 Elbers JMH \& Grootenhuis AJ. New tissue-selective androgens: perspectives in the treatment of androgen deficits. Annals of Endocrinology 200364 183-188.
67 Kumar N, Didolkar AK, Monder C, Bardin CW \& Sundaram K. The biological activity of $7 \alpha$-methyl-19-nortestosterone is not amplified in male reproductive tract as is that of testosterone. Endocrinology 1992130 3677-3683.

68 Anderson RA, Martin CW, Kung AW, Everington D, Pun TC, Tan KC, Bancroft J, Sundaram K, Moo-Young AJ \& Baird DT. $7 \alpha$-methyl-19-nortestosterone maintains sexual behavior and mood in hypogonadal men. Journal of Clinical Endocrinology and Metabolism 199984 3556-3562.

69 Anderson RA, Wallace AM, Sattar N, Kumar N \& Sundaram K. Evidence for tissue selectivity of the synthetic androgen $7 \alpha$-methyl-19-nortestosterone in hypogonadal men. Journal of Clinical Endocrinology and Metabolism 200388 2784-2793.

70 Hamann LG, Mani NS, Davis RL, Wang XN, Marschke KB \& Jones TK. Discovery of a potent, orally active, nonsteroidal androgen receptor agonist: 4-ethyl-1,2,3,4-tetrahydro-6-(trifluoromethyl)8-pyridono[5,6-g-]-quinoline (LG121071). Journal of Medicinal Chemistry 199942 210-212.

71 Rosen J \& Negro-Vilar A. New, non-steroidal, selective androgen receptor modulators (SARMs) with anabolic activity in bone and muscle: improved safety profile. Journal of Musculoskeletal and Neuronal Interactions $20022222-224$.

72 Gao W, Chung K, Kearbey JD, Miller DD \& Dalton JT. Pharmacologic effects of Androxolutamide (GTx-007) on male rats of varying hormonal status. ENDO 2002 - 84th Annual Meeting of the Endocrine Society (June 19-22, San Fransisco) 2002 Abst P2-487.

Received 30 December 2003

Accepted 10 June 2004 